\title{
Assessment of RELAP/SCDAPSIM/MOD3.4 Prediction Capability with Severe Fuel Damage Scoping Test
}

\author{
Noppawan Rattanadecho, ${ }^{1}$ Somboon Rassame, ${ }^{1}$ Kampanart Silva, \\ Chris Allison, ${ }^{3}$ and Judith Hohorst ${ }^{3}$ \\ ${ }^{1}$ Department of Nuclear Engineering, Chulalongkorn University, 254 Phayathai Rd, Pathumwan, Bangkok 10330, Thailand \\ ${ }^{2}$ Thailand Institute of Nuclear Technology (Public Organization), 9/9 Moo 7, Saimoon, Ongkharak, \\ Nakorn Nayok 26120, Thailand \\ ${ }^{3}$ Innovation Systems Software, 2585 Briar Creek Ln., Ammon, Idaho 83406, USA
}

Correspondence should be addressed to Somboon Rassame; somboon.ra@chula.ac.th

Received 12 July 2017; Revised 4 September 2017; Accepted 14 September 2017; Published 25 October 2017

Academic Editor: Arkady Serikov

Copyright (C) 2017 Noppawan Rattanadecho et al. This is an open access article distributed under the Creative Commons Attribution License, which permits unrestricted use, distribution, and reproduction in any medium, provided the original work is properly cited.

The Power Burst Facility (PBF) was designed to provide experimental data to determine the thresholds for failure during accident conditions. Thus, the PBF benchmark using severe accidental analysis codes is essential to designing reactor for current directions. This assessment verified and validated that the RELAP/SCDAPSIM/MOD3.4 code can be used to assess the Severe Fuel Damage Scoping Test (SFD-ST) performed in the PBF facility. This study compares the cladding temperatures and hydrogen production results calculated by the RELAP/SCDAPSIM/MOD3.4 code with experimental data and calculated results from the SCDAP/RELAP5/MOD3.2 and SCDAP/RELAP5/MOD3.3 codes. The interested parameters are cladding temperature and hydrogen production since the cladding temperature affects hydrogen production and consequently influences the accident scenario. The calculated cladding temperatures and hydrogen production results from the RELAP/SCDAPSIM/MOD3.4 code are in a good agreement with the experimental data and are generally more reasonable than the calculated results from the SCDAP/RELAP5/MOD3.2 and SCDAP/RELAP5/MOD3.3 codes. There are some discrepancies in the cladding temperature and hydrogen production results but they are expected.

\section{Introduction}

In 1979, a severe accident occurred at the Three Mile Island Unit 2 (TMI-2) [1]. A failure in the nonnuclear part of the plant system triggered series of some automated responses in the reactor coolant system (RCS) and the relief valve at the top of the pressurizer failed to close when the pressure returned to a proper value. After that, the operators were unaware that cooling water was pouring out of the stuck open valve. The lack of proper water flow allowed the reactor core to become partially uncovered and severely damaged. Fukushima Daiichi nuclear accident occurred in 2011 due to the occurrence of a huge tsunami after a massive earthquake [2]. The earthquake situation affected the electrical power supply lines at the site and the tsunamis caused the massive damage to the site infrastructure resulting in the loss of the cooling system. The above severe accidents significantly destroyed the infrastructure and were potentially harmful to humans and the environment. Consequently, it is necessary to study and understand the progression of severe accidents to prevent the occurrence of severe accidents or mitigate their consequences in case they are unavoidable.

The Power Burst Facility (PBF) was designed to test fuel samples under accident conditions and to learn the implications of fuel failure to safety when operating power reactors. The main purposes of the experiments performed in the PBF facility were to understand the fuel behavior and the generation of hydrogen during a severe accident. The PBF facility was designed to provide experimental data to define the thresholds of failure during postulated accident 
conditions and to understand the failure mechanisms [3]. The Severe Fuel Damage Scoping Test (SFD-ST) was the first large scale severe fuel damage experiment that was performed in PBF $[4,5]$. The objectives of this experiment were to understand the fuel bundle dynamics, the related hydrogen generation, and fission product behavior during transient period.

The RELAP/SCDAPSIM code has been developed by Innovative Systems Software (ISS) and has been used to predict the RCS behavior, thermal hydraulic, and core behavior under normal and accident conditions. The RELAP/ SCDAPSIM code contains improved SCDAP models developed from recent experimental programs, improved numerical analysis, and a three-dimension display. The assessment of RELAP/SCDAPSIM code has been performed with some research reactor [6], PWR core [7], RBMK [8], CANDU $[9,10]$, QUENCH $[11,12]$, and CORA-17 [13]. There are many benchmark studies using RELAP/SCDAPSIM computer program to predict the results of several severe experiments except the SFD-ST test program.

This study is aimed to study and assess the prediction capability of RELAP/SCDAPSIM/MOD3.4 code on the PBF SFD-ST experiment. Section 2 provides the initial conditions and the details that are used to run the code. Section 3 shows the predicted results from the RELAP/SCDAPSIM/MOD3.4 code and a comparison of the predicted data with the experimental results and results from another two versions of SCDAP/RELAP5 codes and a discussion of the results. Section 4 summarizes and gives the important conclusions from this study.

\section{Description of the RELAP/SCDAPSIM/ MOD3.4 Code and the Experiment}

This section provides the details of the code used in this study and experiment used to predict and analyze the results. The RELAP/SCDAPSIM/MOD3.4 code is used to analyze the thermal hydraulic response and core behavior of the Severe Damage Fuel Scoping Test (SFD-ST) conducted in the Power Burst Facility (PBF) at the Idaho National Laboratory, USA.

\subsection{RELAP/SCDAPSIM/MOD3.4. The RELAP/SCDAPSIM} code, designed to predict the behavior of reactor systems during normal and accident conditions, is being developed as part of the international SCDAP Development and Training Program (SDTP) [14]. Innovative Systems Software (ISS) is the administrator for the program. The RELAP/SCDAPSIM/MOD3.4 code used by general user community for production safety analysis runs wide range of transients fast and more reliably than earlier versions of the code. The purpose of the code is to predict core response and the thermal hydraulic response of the reactor coolant system (RCS) during normal operation, design basis, and severe accidents. The RELAP/SCDAPSIM code combines two codes RELAP5 and SCDAP into one code [15]. The RELAP5 model is used to analyze the thermal hydraulic response of the RCS, control system behavior, and rector kinetics and the behavior of some reactor components such as valves and pumps. The
SCDAP model is applied to estimate the behavior of the core and vessel structures under normal and accident conditions. It is also capable of predicting the later stages of a severe accident including the melting of fuel, debris and molten pool formation, vessel interactions, and failed structural vessel.

The RELAP/SCDAPSIM/MOD3.4 code uses the publicly available RELAP5/MOD3.3 and SCDAP/RELAP5/MOD3.2 and 3.3 models developed by the US Nuclear Regulatory Commission in combination with proprietary and some advanced features such as (a) advanced programming and numerical methods, (b) user options, (c) models developed by ISS, and other STDP members.

2.2. Code Nodalization for PBF SFD-ST Experiment [4]. The PBF SFD-ST program was the first experiment in the series of four severe fuel damage tests that was performed to gain some operating experiences for the following test programs. The main purpose was to understand the dynamics of a fuel bundle, hydrogen production during the normal transient phase, and the coolability of the bundle during the reflood phase. The results of the test proved that the instrumentation and procedures used gave usable results and provided informative guidance for the posttest examination and analysis.

The PBF SFD-ST test bundle consisted of 32 fresh pressurized water (PWR) design fuel rods with $0.9114 \mathrm{~m}$ in length and arranged in a $6 \times 6$ array with the corner rods missing surrounded by a shroud with an inner diameter of $127 \mathrm{~mm}$ as shown in Figure 1. The shroud consisted of a zirconia insulator placed between Zircaloy layers. The test train assembly was built by the Pacific Northwest Laboratory (PNL) and assembled at the Idaho National Laboratory (INL), formerly the Idaho National Engineering Laboratory (INEL). The main components were the inlet, outlet, insulated shroud, bundle, flow tube, and closure head. The used instruments were thermocouples, coolant pressure transducers, flow rate meters, and rod-failure pressure switches. The measured elevations were $0.35,0.5$, and $0.7 \mathrm{~m}$ above the bottom of the fuel. The peak temperatures, measured by the thermocouples, were up to $2400 \mathrm{~K}$ for the cladding and $1600 \mathrm{~K}$ for the shroud.

The PBF SFD-ST test had two phases, the high temperature transient (prereflood phase) and reflood phase. For the high temperature transient phase, the initial reactor power was $35 \mathrm{~kW}$ and the initial coolant flow through the bundle was approximately $0.016 \mathrm{l} / \mathrm{s}$. The reactor power was increased from $35 \mathrm{~kW}$ to $93 \mathrm{~kW}$ (maximum power) in the 205 minutes from the beginning of transient phase to the end of the experiment. At approximately 20 minutes after the start of the experiment, the coolant flow rate was increased to be $0.02 \mathrm{l} / \mathrm{s}$. The termination of the transient phase was at approximately 205 minutes at which time the reactor was scrammed. After the occurrence of the reactor scram, the coolant flow rate significantly increased $0.035 \mathrm{l} / \mathrm{s}$ to reduce the bundle temperature. This period was called the reflood phase.

The nodalization scheme of PBF SFD-ST code used for the input code in the calculation is shown in Figure 2. It shows the RELAP5 and SCDAP components in detail [15]. The RELAP5 components are divided into two subparts, the bundle and bypass. In the RELAP5 nodalization of the test 


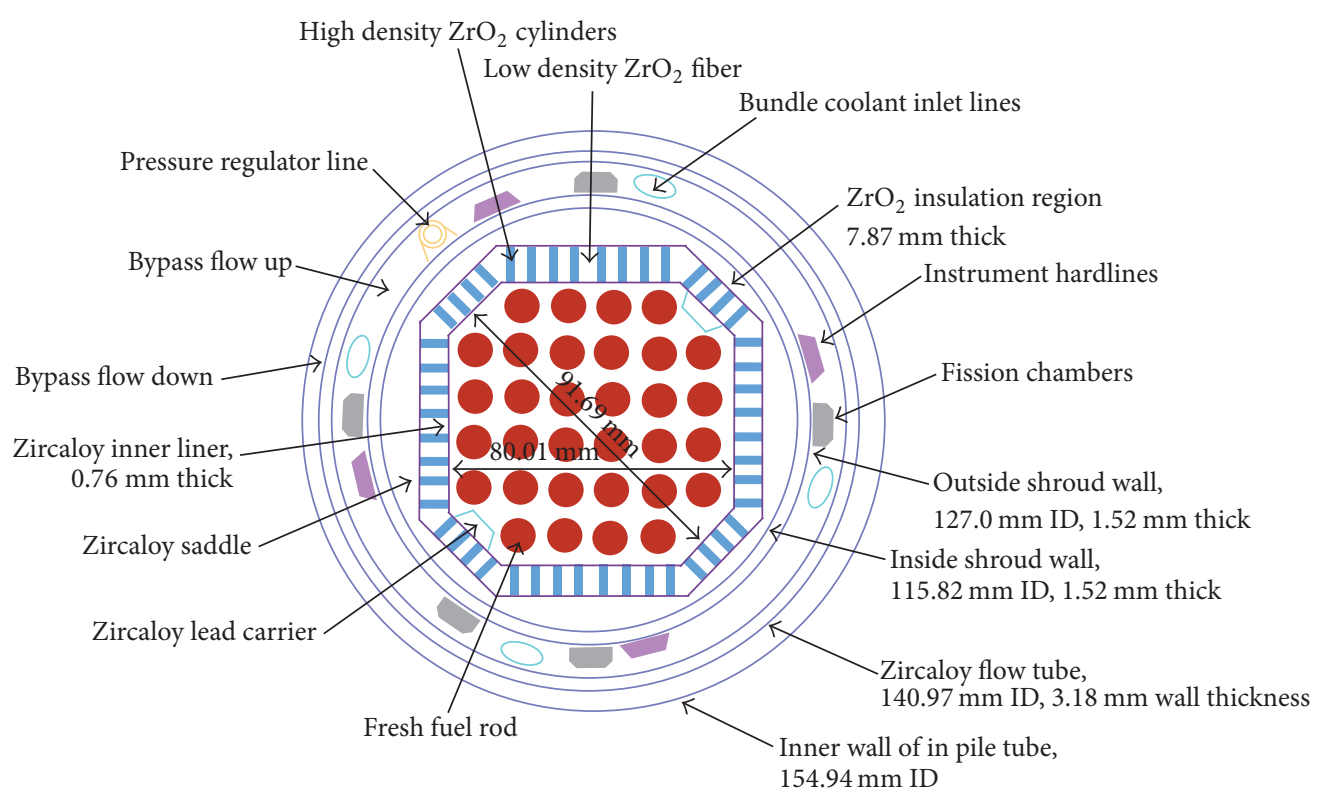

FIGURE 1: Cross section view of SFD-ST shroud and bundle.

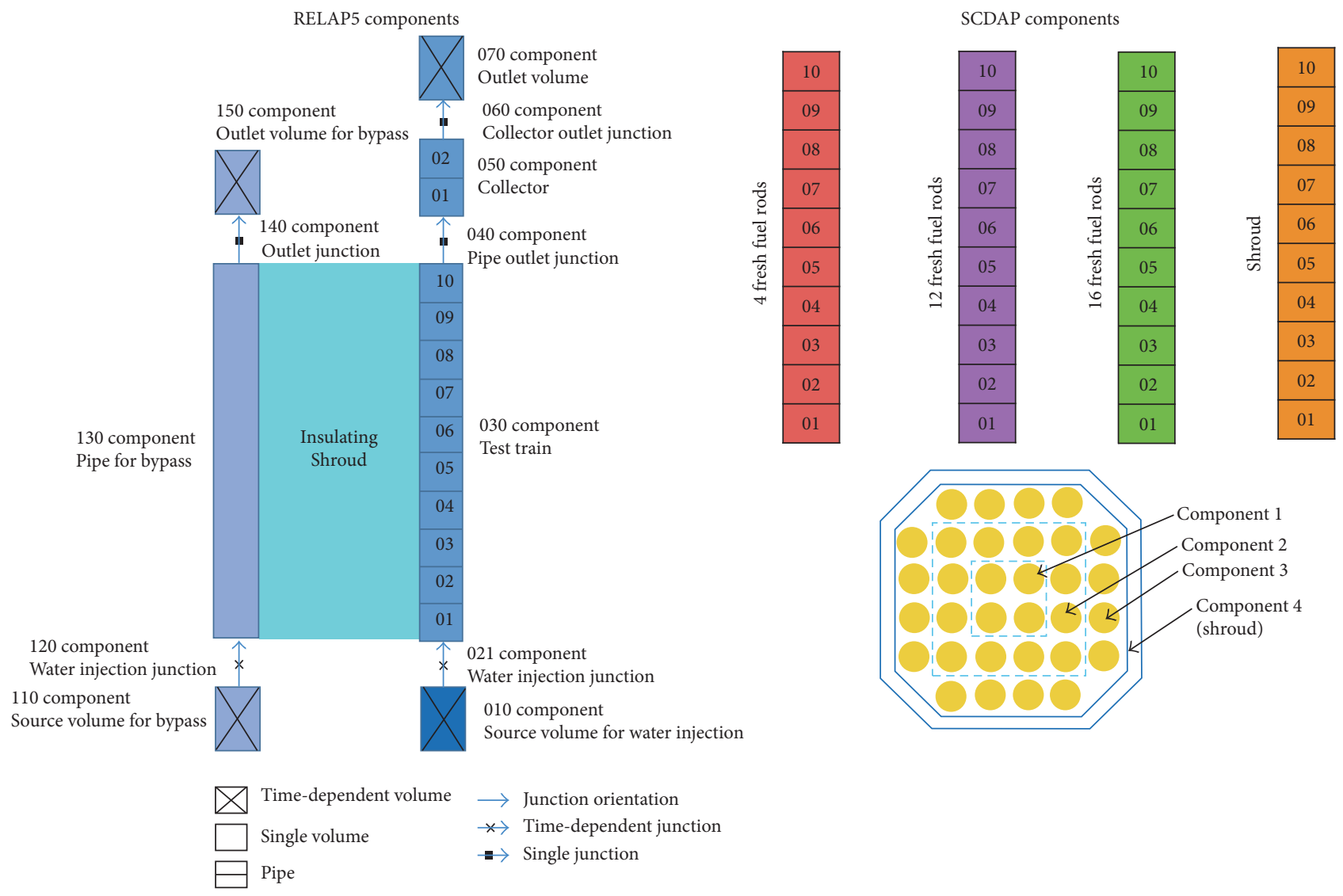

FIGURE 2: Nodalization of the PBF SFD-ST experiment.

bundle, source volume 10 injects water into the test train, pipe volume 30, through junction 021. Pipe volume 30 is divided into $0.1 \mathrm{~m}$ subvolumes. The outlet volume of pipe 30 is connected to the collector, volume 50, by junction 40 .
Volume 50 has two $0.5 \mathrm{~m}$ in length subvolumes. The outlet volume 050 is connected to volume 070 by junction 060 . In the bypass part, source volume 110 is connected to pipe component volume 130, to inject water into the bypass region 


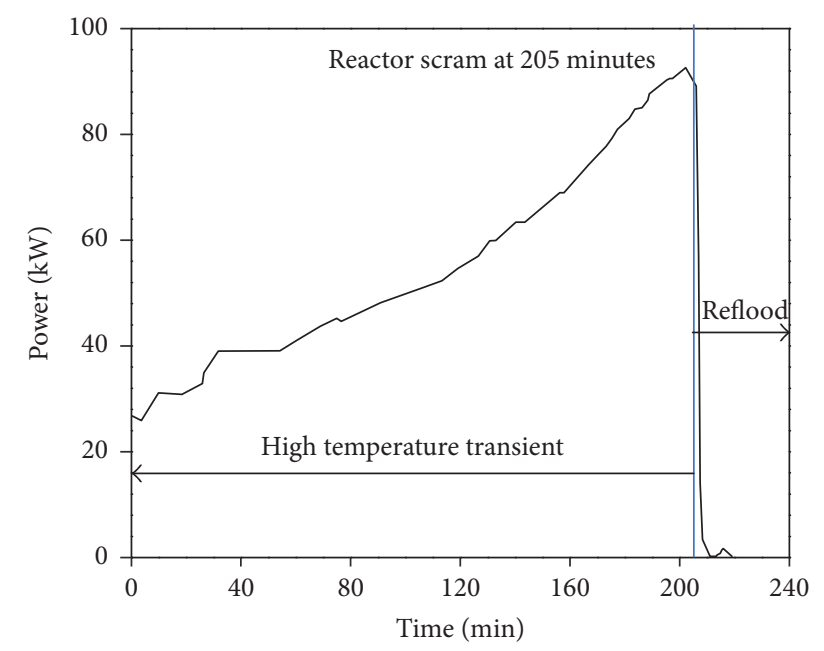

Figure 3: Two phases of the experiment, high temperature transient and reflood phase, in view of the bundle power-time profile.

TABLE 1: Examples of boundary conditions used in the input code.

\begin{tabular}{lc}
\hline $\begin{array}{l}\text { Boundary } \\
\text { conditions }\end{array}$ & Values \\
\hline Bundle description & 32 fresh rods \\
Power $(\mathrm{kW})$ & $35-90$ \\
Pressure $(\mathrm{MPa})$ & $6.6-6.7$ \\
$\begin{array}{l}\text { Nominal inlet flow } \\
\text { rate }(\mathrm{L} / \mathrm{s})\end{array}$ & 0.02 \\
$\begin{array}{l}\text { Cooldown } \\
\text { procedure }\end{array}$ & After reactor scram, $0.02 \mathrm{~L} / \mathrm{s} \mathrm{reflood}$ \\
\hline
\end{tabular}

through junction 120 . Volume 130 is $1 \mathrm{~m}$ in length and is connected to sink volume, 150 by junction 140 .

Four SCDAP components were used to model the PBF SFD-ST test bundle. Components 1, 2, and 3 represent the inner ring of 4 fresh fuel rods, the middle ring of 12 fuel rods, and the outer ring of 16 fuel rods, and component 4 represents the shroud. Each component has 10 axial nodes $0.1 \mathrm{~m}$ in length. The fuel rod material used in this calculation was fresh UO2. The fuel pellet, outer cladding, and inner cladding radiuses were $4.13 \mathrm{~mm}, 4.81 \mathrm{~mm}$, and $4.22 \mathrm{~mm}$, respectively.

2.3. Boundary Conditions. Figure 3 demonstrates two phases of the experiment, high temperature transient phase (prereflood phase), and reflood phase in view of the bundle powertime profile. Figure 4 and Table 1 give some examples of boundary conditions for the PBF SFD-ST experiment used in the input code. The key boundary conditions are bundle pressure, bundle inlet flow rate, power profile, and bundle inlet temperature. The power significantly increased from $35 \mathrm{~kW}$ at the beginning of the experiment to a maximum power of $93 \mathrm{~kW}$ when the reactor was scrammed. The reactor power was reduced significantly after reactor scram at about 205 minutes. The first 205 minutes of the experiment was called the high temperature transient. The reflood phase started after the reactor was scrammed. The coolant flow rate was about $0.02 \mathrm{l} / \mathrm{s}$ at $525 \mathrm{~K}$ during the transient phase from the
TABLE 2: Damage level states classified by the code.

\begin{tabular}{lc}
\hline Damage level codes & Damage states \\
\hline 0.0 & Intact geometry \\
0.1 & Rupture due to ballooning \\
0.2 & Rubble (fragmented) \\
0.4 & Cohesive debris \\
1.0 & Molten pool \\
\hline
\end{tabular}

start of the experiment to 205 minutes. Afterwards, during the reflood phase the coolant flow rate was increased from $0.02 \mathrm{l} / \mathrm{s}$ to $0.035 \mathrm{l} / \mathrm{s}$ to cool the hot test fuel. The bundle inlet temperature was a constant $525 \mathrm{~K}$ during the transient phase and was reduced to about $514 \mathrm{~K}$ at 205 minutes, the time of reactor scram. Figure 5 displays the flow rate and temperature boundary conditions of the bypass line. The temperature trend in the bypass was similar to the bundle but the flow rate in the bypass was quite constant after 20 minutes, whereas the flow rate in the bundle was dramatically increased at reactor scram. The boundary conditions of the bundle are given in source volume 010 and the boundary conditions for the bypass are given in source volume 110 .

2.4. Focused Parameters. The predictive capability of RELAP/ SCDAPSIM/MOD3.4 is assessed by comparing the calculated results with the PBF SFD-ST experimental results and calculated results from other comparable codes such as the SCDAP/RELAP/MOD3.2 and SCDAP/RELAP/MOD3.3 code. The parameters being focused on in this paper are (1) the collapsed water level, (2) cladding temperatures, and (3) hydrogen production. It is known that the water level in reactor is a crucial parameter which affects the temperature of the cladding temperature. An accurate prediction of the water level in the core results in an acceptably accurate prediction of the core temperature.

Hydrogen is normally produced from the reaction of Zircalloy cladding with steam when the bundle temperature reaches $1273 \mathrm{~K}$ [17]. The production of hydrogen usually occurs during a severe accident. Since the cladding temperature is a key parameter in determining hydrogen production rate, the accurate prediction of cladding temperature leads to the good estimation of hydrogen production. Actually, the cladding or fuel temperature in a damage state is interested, but there are limitations in their measurements, since the thermocouples failed to measure at temperatures above $2000 \mathrm{~K}$. Analysis the comparison provides the understanding of the core behavior and the phenomena and some limitation of codes.

Additionally, this paper shows some examples of the calculated temperature distribution and damage level states of the fuel rod and cladding by the RELAP/ SCDAPSIM/MOD3.4 code. The five damage level states are defined in Table 2. The " 0.0 " code represents intact geometry, that is, no change in the geometry of fuel bundle. The "0.1" code indicates rupture of the cladding due to ballooning has occurred. The " 0.2 " code indicates the formation of rubble debris and fragmentation occurred. The " 0.4 " and "1.0" codes indicate the formation of cohesive debris and a molten pool, 


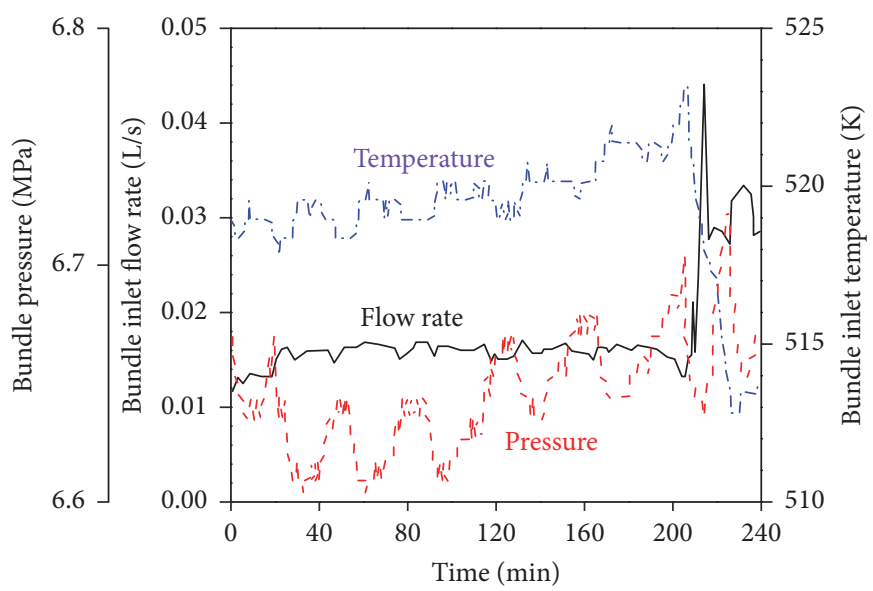

Figure 4: Boundary conditions used in the input code.

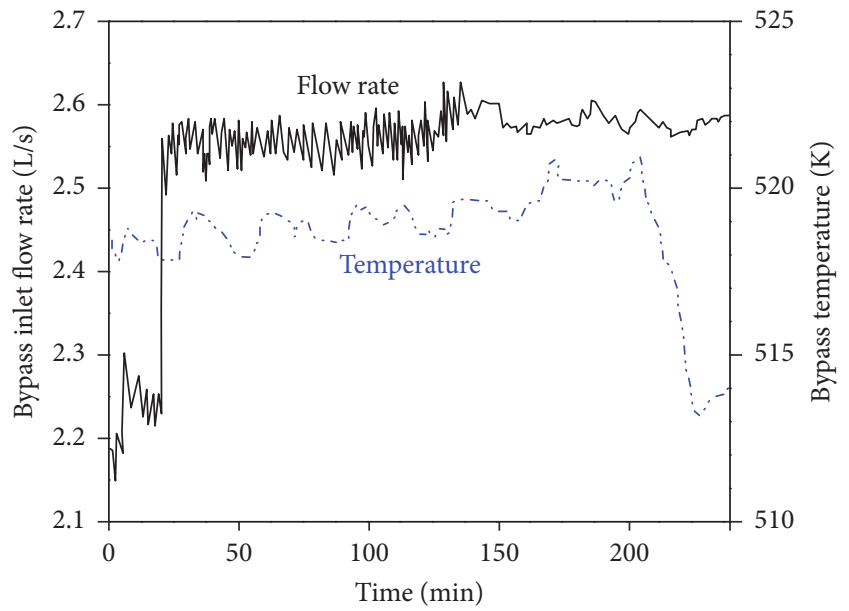

FIGURE 5: Boundary conditions of the bypass line used in the input code.

respectively. It is known that fuel and cladding temperatures have a relationship to the occurring damage level states of the fuel rod and cladding. Besides, damage level states have depended on excessive internal pressure of fuel rod [5].

\section{Analysis Results}

The calculated results from the RELAP/SCDAPSIM/MOD3.4 code are compared to the measured data and the calculated results from the SCDAP/RELAP5/MOD3.2 and SCDAP/RELAP5/MOD3.3 code $[4,16]$. Information pertaining to the total hydrogen released during the experiment that is used to compare the RELAP/SCDAPSIM/MOD3.4 calculated values to the measured results taken from available sources $[18,19]$. The use of different publications for the information of hydrogen productions is due to the fact that this related information was published latterly after the completion of the Postirradiation Examination (PIE) of the damaged bundle.

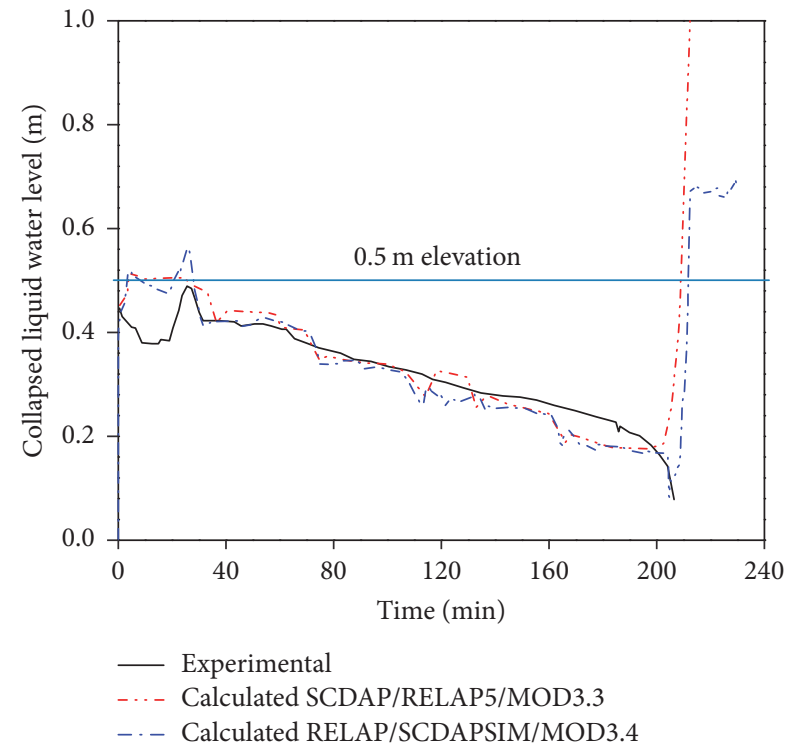

FIGURE 6: Comparison of experimental and calculated water levels in the bundle.

3.1. Cladding Temperatures. This subsection describes the results pertaining to the cladding temperatures. Figure 6 shows measured the collapsed liquid water levels in the bundle during the experiment and those calculated by the SCDAP/RELAP5/MOD3.3 and RELAP/SCDAPSIM/ MOD3.4 code. The values for the water level are based on the interface between the two-phase region at the top of the bundle and the single-phase region at the bottom. The experimental water level results for the reflood phase of the experiment are not included in this paper (only high temperature transient phase). In contrast, the temperature values calculated by the SCDAP/RELAP5/MOD3.3 and RELAP/SCDAPSIM/MOD3.4 code include both the high temperature transient and reflood phases. As shown in Figure 6, the SCDAP/RELAP5/MOD3.3 and RELAP/ SCDAPSIM/MOD3.4 codes overpredict the water level during the initial 40 minutes of the experiment. If the water 


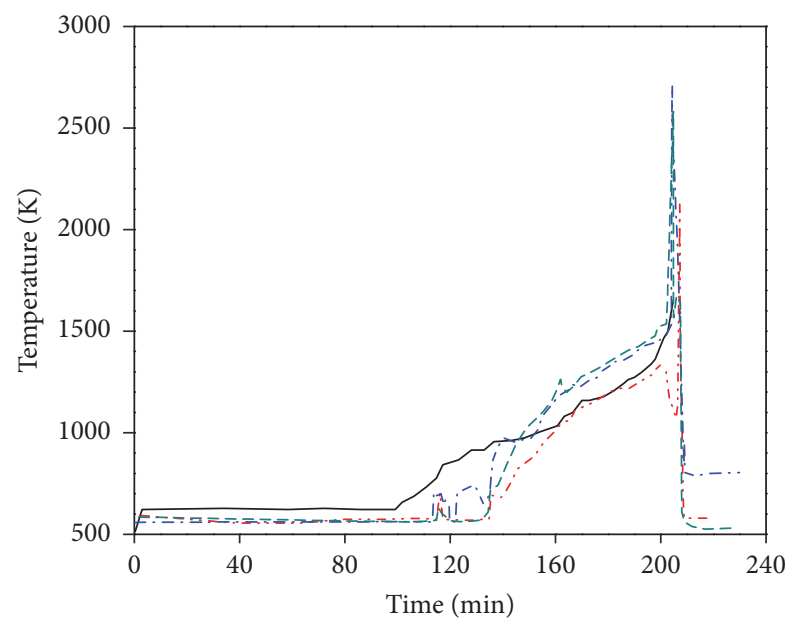

At $0.35 \mathrm{~m}$ elevation from the bottom

- Experimental

- - - Calculated SCDAP/RELAP5/MOD3.2

-... Calculated SCDAP/RELAP5/MOD3.3

- - - Calculated RELAP/SCDAPSIM/MOD3.4

Figure 7: Comparison of measured and calculated cladding temperatures at $0.35 \mathrm{~m}$ elevation.

level is measured correctly during those two periods, the coolant flow rate during the first 40 minutes which is used as the initial flow boundary conditions in RELAP/SCDAPSIM calculation may not be sufficiently accurate. This may result in the overestimation of water level during the initial phase. It is noted that the coolant flow rate during 40 minutes of the experiment was relatively low compared to the flow rate after 40 minutes of experiment. After 40 minutes, the values predicted by both codes are generally similar to the experimental values. During the reflood phase, the both codes are able to predict well the water level but the experimental water level is not measured due to the failure of the instrumentation. The calculated cladding temperatures by the RELAP/SCDAPSIM/MOD3.4 code are compared to the temperatures measured during the experiment and the calculated temperatures from the SCDAP/RELAP5/MOD3.2 and SCDAP/RELAP5/MOD3.3 codes at 0.35, 0.5, and $0.7 \mathrm{~m}$ elevations. All versions of the SCDAP/RELAP5 and RELAP/SCDAPSIM codes calculate a temperature at the midpoint of an axial node (each axial node in this assessment calculation is 0.1 in length). Therefore, to obtain a predicted temperature at the measured elevations of 0.5 and 0.7 , a linear interpolation is performed between the calculated temperature from the axial node below and above the desired elevation. (For example, for the $0.5 \mathrm{~m}$ elevation the linear interpolation is performed between the calculated temperatures at the $0.45 \mathrm{~m}$ and $0.55 \mathrm{~m}$ elevations, and for the $0.7 \mathrm{~m}$ elevation the interpolation was between the calculated temperatures at the 0.65 and $0.75 \mathrm{~m}$ elevations.) Figures 7, 8, and 9 show the comparisons of the cladding temperatures at $0.35,0.5$, and $0.7 \mathrm{~m}$ elevations, respectively.

As shown in Figure 7, for the cladding temperatures at $0.35 \mathrm{~m}$ elevation, dry-out occurred 100 minutes from the

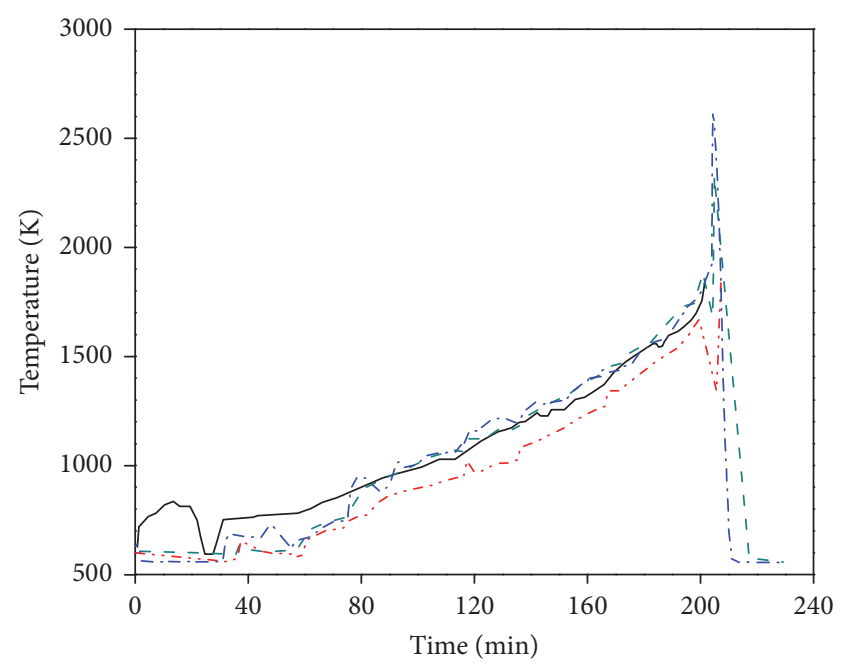

At 0.5 m elevation from the bottom
- Experimental
- - - Calculated SCDAP/RELAP5/MOD3.2
-.- Calculated SCDAP/RELAP5/MOD3.3
- - - Calculated RELAP/SCDAPSIM/MOD3.4

Figure 8: Comparison of measured and calculated cladding temperatures at $0.5 \mathrm{~m}$ elevation.

beginning of the transient. From 100 minutes to 200 minutes the temperature continuously increases until the limitation of instrumentation is reached and the reactor is scrammed. The cladding calculated temperature fluctuates slightly between 100 and 140 minutes. The reactor was scrammed at 205 minutes.

As shown in the Figure 8, the sudden changes of measured cladding temperature at $0.5 \mathrm{~m}$ elevation are observed during approximately 20 to 30 minutes while the opposite trend of measured water level changes around $0.5 \mathrm{~m}$ elevation is also observed during that period of time. This indicates that the cladding temperature is significantly affected by the liquid water level. The calculated temperatures from the codes being compared in this study show a small amount of fluctuation between 40 and 60 minutes with the predicted trends closely matching the measured temperature up to the time of reactor scram.

As shown in Figure 9, the predicted cladding temperatures at $0.7 \mathrm{~m}$ elevation from the three codes follow the measured temperature reasonably well up to thermocouple failure. The calculated temperatures fluctuate moderately from 0 to 30 minutes. From 30 minutes until the end of the transient phase, the predicted temperature steadily increases.

After the end of the transient phase, the bundle is reflooded. During this phase, changes in the bundle geometry occurred. During the experiment, the instrumentation could not measure the data during the reflood phase due to the measureable limitation of the instruments, but the RELAP/SCDAPSIM/MOD3.4 code is capable of predicting bundle behaviors. During the reflood phase, the calculated water levels increase rapidly depending on the inlet flow. During the reflood phase starting at 205 minutes, the cladding temperature at all elevations increases rapidly for several 


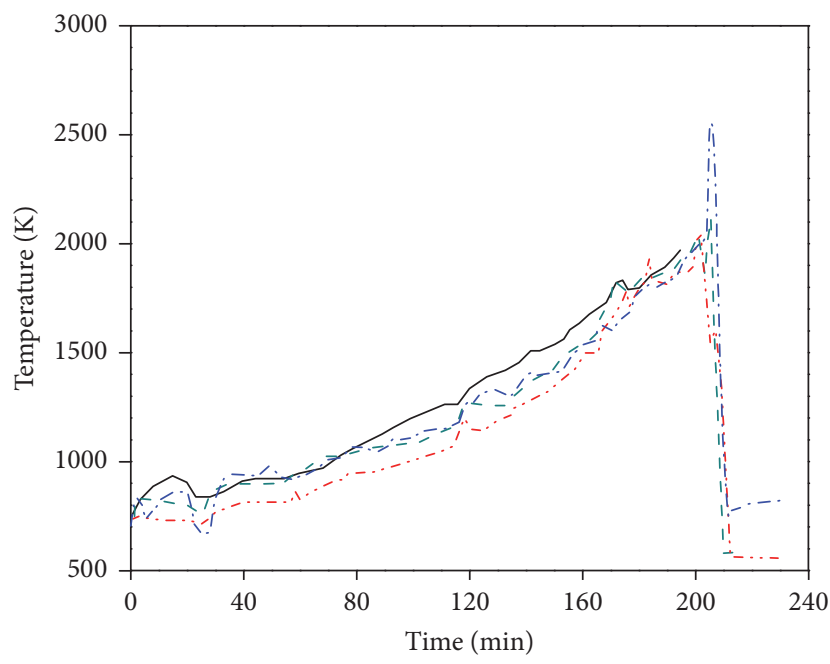

At $0.7 \mathrm{~m}$ elevation from the bottom

- Experimental

- . - Calculated SCDAP/RELAP5/MOD3.2

-..- Calculated SCDAP/RELAP5/MOD3.3

- - - Calculated RELAP/SCDAPSIM/MOD3.4

Figure 9: Comparison of measured and calculated cladding temperatures at $0.7 \mathrm{~m}$ elevation.

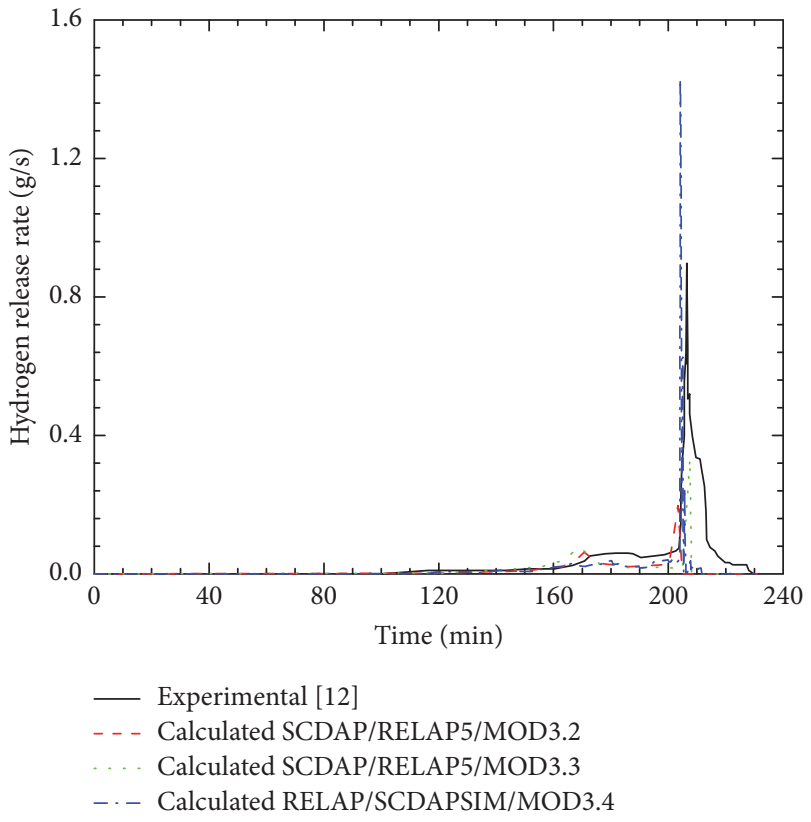

FIGURE 10: Comparison of hydrogen release rate measured in the experiment and predicted by the codes.

minutes before it dramatically decreases to about $500 \mathrm{~K}$ by 210 minutes.

From the Figures 7, 8, and 9, the calculated RELAP/ SCDAPSIM/MOD3.4 cladding temperatures at all elevations are in a good agreement with experiment and are more accurate than those calculated by the SCDAP/RELAP/MOD3.2 and SCDAP/RELAP/MOD3.3 code. There are some uncertainties in the calculated values by the code. The results of

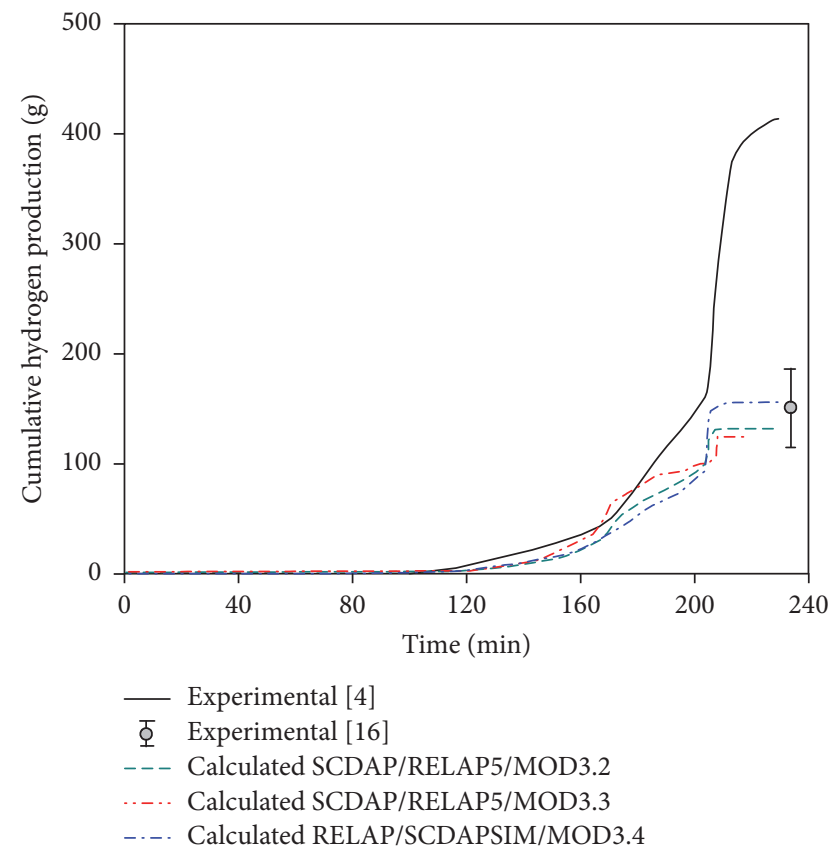

FIGURE 11: Comparison of cumulative hydrogen production measured in the experiment and predicted by the codes.

the RELAP/SCDAPSIM/MOD3.4 code are generally more reliable due to a better prediction of the interface water level and the improved fuel assembly behavior and in-vessel melt retention models.

3.2. Hydrogen Production. Figures 10 and 11 display the hydrogen production rate and hydrogen accumulated production, respectively. The three calculated results are in good agreement with measured trend in prereflood phase only. During the reflood phase, it can be seen that the calculated results were unreasonable with the measured results. The significant uncertainties of hydrogen production measurement during the reflood phase need to be further investigated in the details or the oxidation and hydrogen production correlations and related models utilized in the RELAP/SCDAPSIM/MOD3.4 may need to have a further improvement.

Table 3 shows accumulated hydrogen production in grams predicted by the three versions of the code being compared in this paper and the measured quantity. In Table 3, there are 2 columns for each version of the code and the measured data. One column gives the total hydrogen produced during the prereflood phase and another provides the total hydrogen released in the experiment. In the experiment, only the total quantity of hydrogen produced was measured. The measured total hydrogen produced from reference [4], online measurements, was varied from 235 to $515 \mathrm{~g}$. The total hydrogen based on reference [16] was $150 \pm 35 \mathrm{~g}$. The total calculated hydrogen production of RELAP/SCDAPSIM/MOD3.4 was $155 \mathrm{~g}$.

The calculated RELAP/SCDAPSIM/MOD3.4 results are in reasonably good agreement with experimental although 


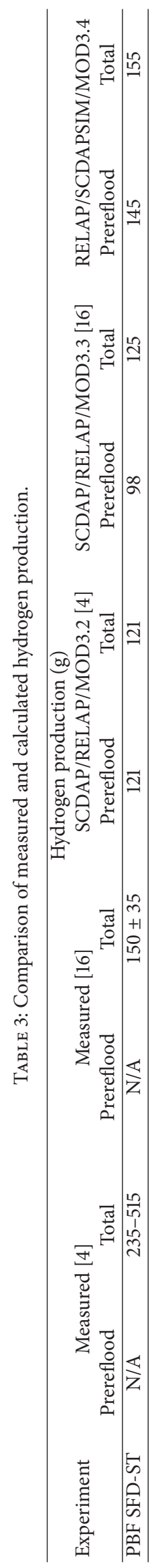




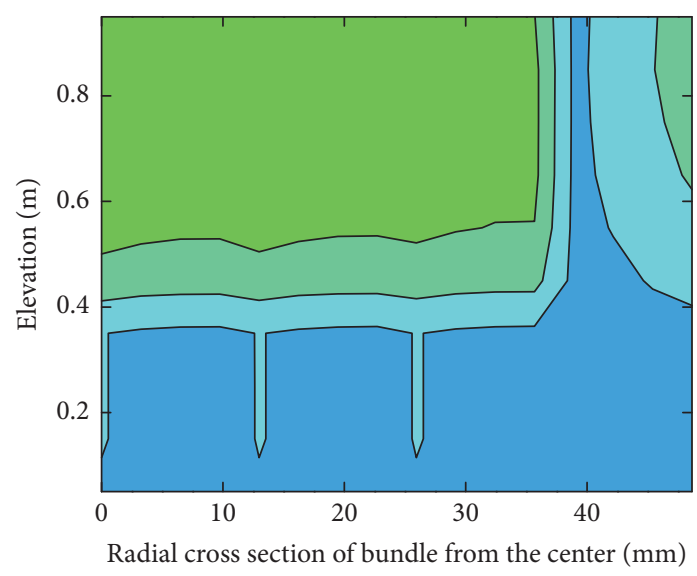

(a) At 80 minutes

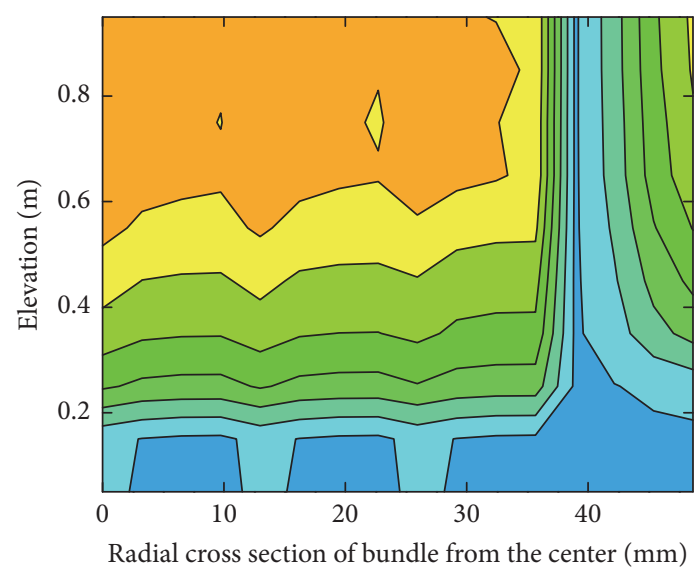

(c) At 190 minutes

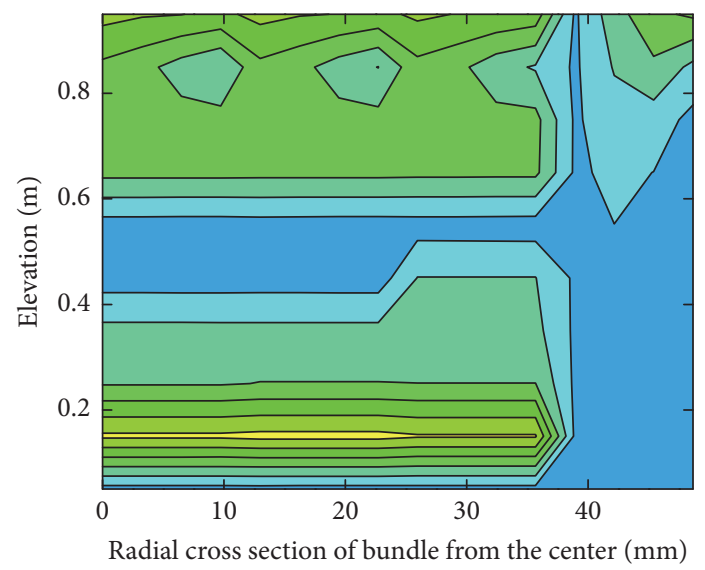

(e) At 210 minutes

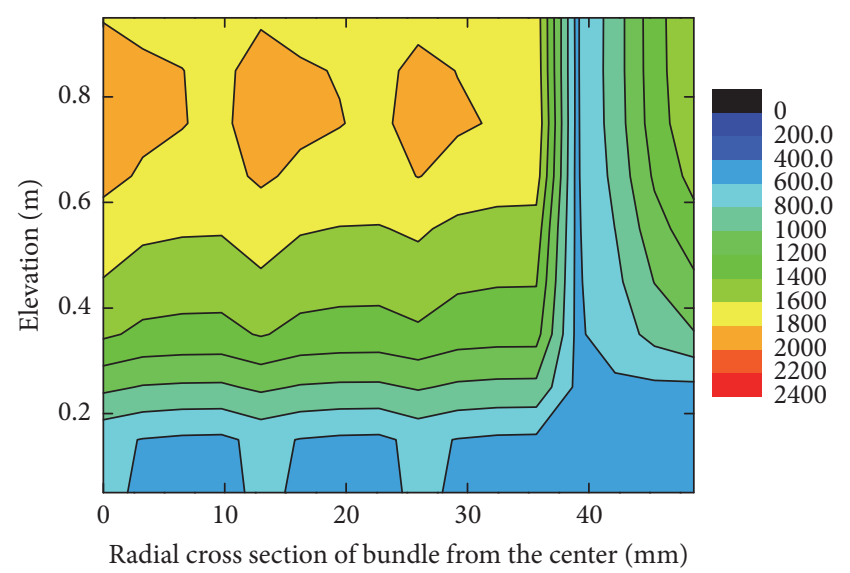

(b) At 180 minutes

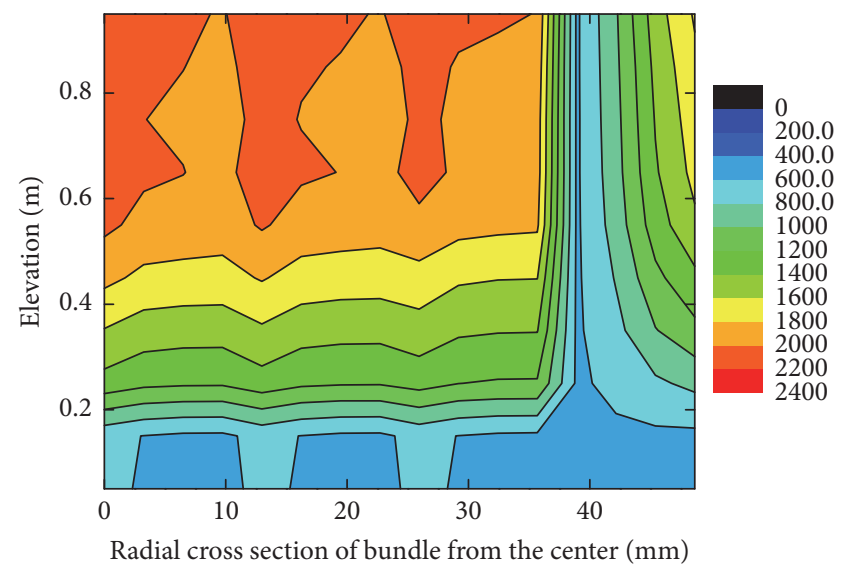

(d) At 200 minutes

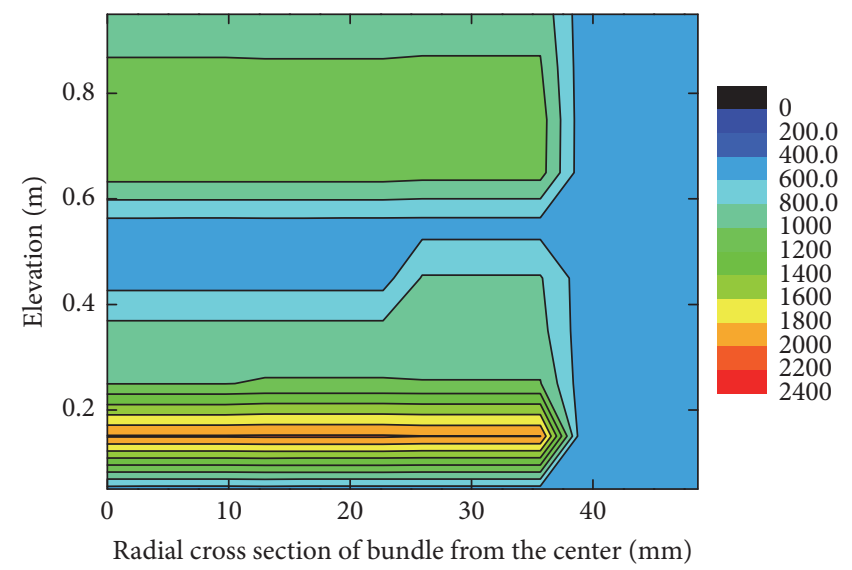

(f) At 220 minutes

FIGURE 12: Temperature distribution of fuel bundle and shroud predicted by the RELAP/SCDAPSIM/MOD3.4 code.

there were some uncertainties. A more accurate prediction of the cladding temperatures led to a better prediction of hydrogen production.

3.3. Temperature Distribution. Figure 12 shows the axial and radial distribution of temperature from the bundle center to the outer shroud at $80,180,190,200,210$, and 220 minutes from the beginning of the experiment, represented by (a), (b), (c), (d), (e), and (f), respectively. The distance from central bundle to the outer shroud was 0 to $48.635 \mathrm{~mm}$. The bundle is about $40 \mathrm{~mm}$ in radius and it is divided into 3 components in same radius. The shroud was $8.63 \mathrm{~mm}$ in radius. The figure shows the changing temperature distributions axially and radially at ten elevations in the bundle (measured from 


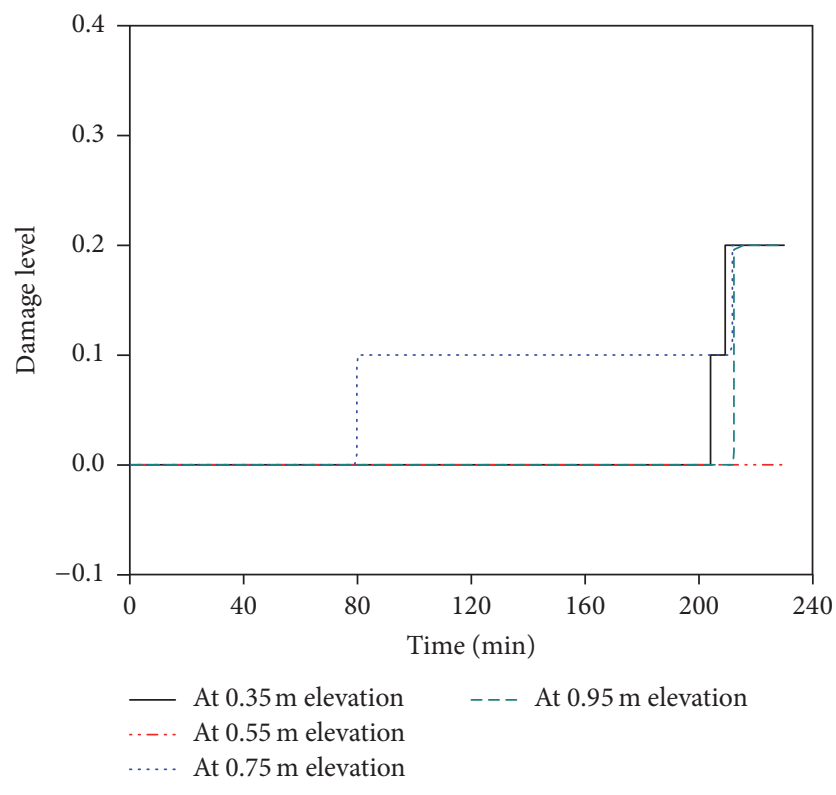

FIGURE 13: Damage level states of fuel bundle predicted by the RELAP/SCDAPSIM/MOD3.4 code.

0.05 to $0.95 \mathrm{~m}$ ). In the figure, (a), (b), (c), and (d) show the bundle temperature distribution prior to reactor scram; (e) and (f) show the distribution for two periods after scram, the first one 5 minutes after scram and the other 10 minutes later.

As shown in the Figure 12, maximum bundle temperatures are between 0.70 and $0.80 \mathrm{~m}$ elevations due to accumulated heat of lower elevations and delayed time of coolant (fed inlet coolant from lowest elevation first). There is gap between bundle and shroud, so the gap distance is about 38 to $40 \mathrm{~mm}$. At 80 minutes, the maximum temperature is about $1130 \mathrm{~K}$ at between 0.70 and $0.80 \mathrm{~m}$ elevations. At 180,190 , and 200 minutes, before occurring reactor scram (205 minutes), the maximum temperatures are about 1850, 1959, and $2163 \mathrm{~K}$ at between 0.70 and $0.80 \mathrm{~m}$ elevations and temperatures at every elevation increase at the following time points. At 210 and 220 minutes, after occurring reactor scram, temperatures decrease due to the increased inlet coolant flow rate $(0.035 \mathrm{l} / \mathrm{s})$. At between 0.1 and $0.2 \mathrm{~m}$ elevations, the temperatures are at maximum value since accumulated major melts possibly occurred at the bottom elevation.

3.4. Damage Level States, Temperature, and Time of Cladding Rupture. Figure 13 shows damage level states of fuel bundle at $0.35,0.55,0.75$, and $0.95 \mathrm{~m}$ elevations based on the RELAP/SCDAPSIM/MOD3.4 code prediction. The maximum damage level state for all elevations was " 0.2 ," defined as fuel bundle rubble. At $0.35 \mathrm{~m}$ elevation, the fuel bundle ruptured at reactor scram and immediately changed to rubble. At $0.55 \mathrm{~m}$ elevation, the fuel bundles retained intact geometry during experiment. At $0.75 \mathrm{~m}$ elevation, rupture occurred between 80 and 205 minutes from the beginning of the experiment forming rubble debris after reactor scram. At $0.95 \mathrm{~m}$ elevation, rubble debris formed after reactor scram. The first rupture of fuel rod and cladding occurred at $0.75 \mathrm{~m}$ elevation at about 80 minutes where this point was maximum temperature of all elevation at this time. At 0.35 , 0.75 , and $0.95 \mathrm{~m}$ elevations, the last damage level state of rubble and fragmented of fuel bundle occurred while there are not changes in fuel bundle and cladding geometry only at $0.55 \mathrm{~m}$ elevation during the test period. This may be slightly different with the obtained results from the radiograph of fuel bundle geometry after the test performing with which the fragment rods are founded along the fuel bundle length [4].

Table 4 shows the results of temperature and time of cladding rupture. The results in the INL reference indicated that fuel rod rupture occurred at about 78 to 87 minutes with maximum cladding temperatures between 1000 and $1200 \mathrm{~K}$ [4]. The experimental results reported in another reference stated that the measured time when cladding rupture occurred was between 90 and 104 minutes from the beginning of experiment at a rupture temperature between 1150 and $1200 \mathrm{~K}$ [5]. The SCDAP/RELAP/MOD3.3 code predicted the cladding rupture to occur between 100 and $106 \mathrm{~min}$ utes and the predicted rupture temperature is about $1050 \mathrm{~K}$ [16]. The RELAP/SCDAPSIM/MOD3.4 code estimates the cladding rupture beginning at 80 minutes and the rupture temperature at $1130 \mathrm{~K}$. Therefore, the calculated results predicted by the RELAP/SCDAPSIM/MOD3.4 code are quite reliable.

\section{Conclusion}

This paper shows the assessment of prediction capability of the RELAP/SCDAPSIM/MOD3.4 code (developed by Innovative Systems Software) focusing on cladding temperatures and hydrogen production in the PBF SFD-ST experiment. The calculated fuel and cladding temperatures and hydrogen production by the RELAP/SCDAPSIM/MOD3.4 code are compared with experimental results and those parameters calculated by other comparable codes such as the SCDAP/RELAP/MOD3.2 and SCDAP/RELAP/MOD3.3 codes.

The calculated cladding temperatures by the RELAP/ SCDAPSIM/MOD3.4 code are generally in a good agreement with the experiment results and more reasonable than those predicted by the SCDAP/RELAP5/MOD3.2 and 3.3 codes. The accurate predicted interface liquid level is attributed to the acceptable predicated cladding temperatures. The bundle and shroud calculated temperature distribution showed the RELAP/SCDAPSIM/MOD3.4 calculated temperatures in detail. The calculated hydrogen production results are reasonable with experimental data. The damage level states are sufficiently corresponded to the experimental results. There are some discrepancies in the predicted cladding temperatures, damage level, and hydrogen production due to uncertainties in the boundary conditions and limitation of the current codes capability. 


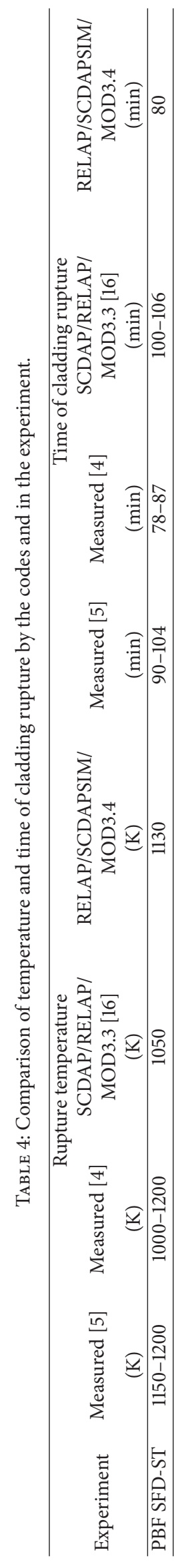




\section{Conflicts of Interest}

The authors declare that there are no conflicts of interest regarding the publication of this paper.

\section{Acknowledgments}

This research was supported by the Graduate School, Chulalongkorn University, under the program of Research Assistant Scholarship.

\section{References}

[1] Nuclear Regulatory Commission Special Inquiry Group, Volume I Three Mile Island: A Report to the commissioners and to The Public, Nuclear Regulatory Commission Special Inquiry Group, 1979.

[2] Y. Amano, The Fukushima Daiichi Accident, International Atomic Energy Agency, 2011.

[3] J. I. M. Damian, A. Weir, V. L. Putnam, and J. D. Bess, "Power Burst Facility: U(18)O2-CaO-ZrO2 Fuel Rods in Water," Tech. Rep. INL/EXT-09-15446, 2009.

[4] A. D. Knipe, S. A. Ploger, and D. J. Osetek, PBF Severe Fuel Damage Scoping Test-Test Results Report, EGG Idaho Inc, Idaho Falls, Idaho, USA, 1986.

[5] L. J. Siefken, "Models for the Configuration and Integrity of Partially Oxidized Fuel Rod Cladding at High Temperatures Final Design Report," Tech. Rep. INEEL/EXT-99-00107, 1999.

[6] A. R. Antariksawan, M. Q. Huda, T. Liu, J. Zmitkova, C. M. Allison, and J. K. Hohorst, "Validation of RELAP/SCDAPSIM/ MOD3.4 for research reactor applications," in Proceedings of the 13th International Conference on Nuclear Engineering, Beijing, China, May 2005.

[7] C. M. Allison and J. K. Hohorst, "An assessment of effectiveness of core exit temperatures with respect to PWR core damage state using RELAP/SCDAPSIM/MOD3.4," Nuclear Engineering and Design, vol. 238, no. 7, pp. 1547-1560, 2008.

[8] A. Kaliatka and E. Uspuras, "Development and testing of RBMK-1500 model for BDBA analysis employing RELAP/ SCDAPSIM code," Annals of Nuclear Energy, vol. 35, no. 6, pp. 977-992, 2008.

[9] M. Mladin, D. Dupleac, and I. Prisecaru, "SCDAP/RELAP5 application to CANDU6 fuel channel analysis under postulated LLOCA/LOECC conditions," Nuclear Engineering and Design, vol. 239, no. 2, pp. 353-364, 2009.

[10] D. Dupleac, M. Mladin, and I. Prisecaru, "Generic CANDU 6 plant severe accident analysis employing SCAPSIM/RELAP5 code," Nuclear Engineering and Design, vol. 239, no. 10, pp. 20932103, 2009.

[11] T. Kaliatka, A. Kaliatka, V. Vileiniškis, and E. Ušpuras, "Modelling of QUENCH-03 and QUENCH-06 experiments using RELAP/SCDAPSIM and ASTEC codes," Science and Technology of Nuclear Installations, vol. 2014, Article ID 849480, 13 pages, 2014.

[12] H. Madokoro, K. Okamoto, and Y. Ishiwatari, "SCDAP model improvement with QUENCH-06 analysis," in Proceedings of the 2014 22nd International Conference on Nuclear Engineering, ICONE 2014, Prague, Czech Republic, July 2014.

[13] H. Madokoro, "Assessment of RELAP/SCDAPSIM/MOD3.5 against the BWR core degradation experiment CORA-17," in Proceedings of the 10th International Topical Meeting on Nuclear
Thermal-Hydraulics, Operation and Safety, Okinawa, Japan, 2014.

[14] C. M. Allison and J. K. Hohorst, "Role of RELAP/SCDAPSIM in nuclear safety," Science and Technology of Nuclear Installations, vol. 2010, Article ID 425658, 17 pages, 2010.

[15] N. Rattanadecho, S. Rassame, K. Silva, C. Allison, and J. Hohorst, "Assessment of RELAP/SCDAPSIM/MOD3.4 Prediction Capability with Severe Fuel Damage Scoping Test: Focusing on Reactor Core Temperatures and Hydrogen Production," in Proceeding the 11th International Topical Meeting on Nuclear Reactor Thermal Hydraulics, Operation and Safety, Gyeongju, Korea, October 2016.

[16] L. J. Siefken, E. W. Coryell, E. A. Harvego, and J. K. Hohorst, Assessment of Modeling of Reactor Core Behavior During Severe Accidents, daho National Engineering and Environmental Laboratory, Idaho Falls, Idaho, USA, 2001.

[17] A. L. Camp, J. C. Cummings, M. P. Sherman et al., "Light Water Reactor Hydrogen Manual," NUREG/CR-2726, 1983.

[18] B. A. Cook, P. A. Kalish, and D. M. Tow, Posttest Examination of the Severe Fuel Damage Scoping Test Bundle Geometry, Idaho National Engineering Laboratory, Idaho Falls, Idaho, USA, 1984.

[19] P. Hofmann, "Metallographic Examination of the Severe Fuel Damage Scoping Test (SFD-ST) Fuel Rod Bundle Cross Sections," NUREG/CR-5119, July 1988. 


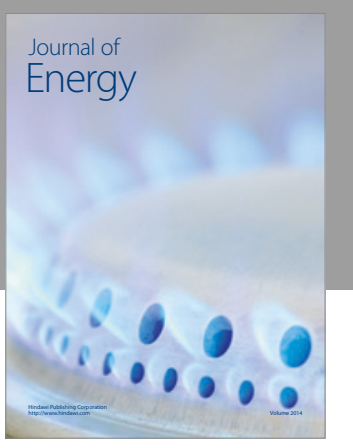

Journal of

Industrial Engineering
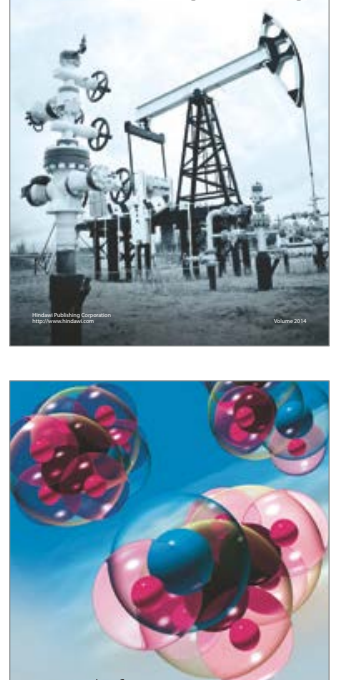

Fuels
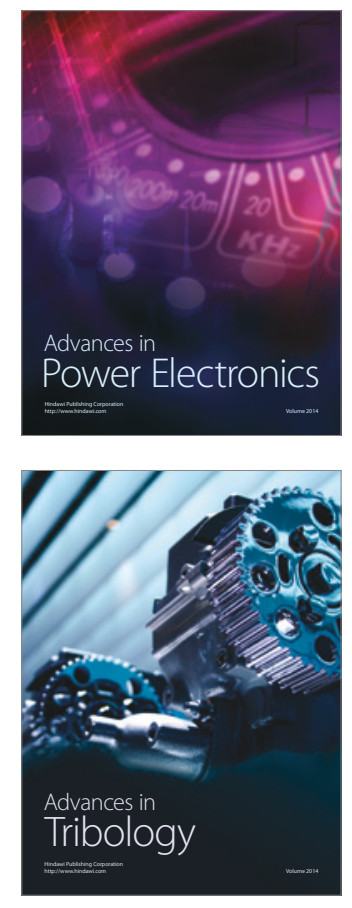
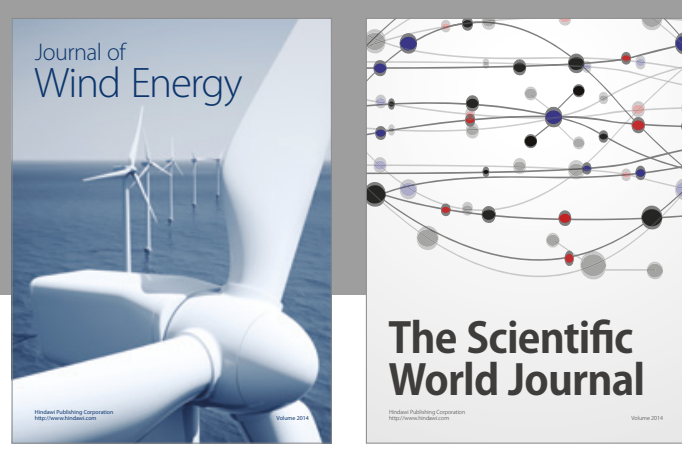

The Scientific World Journal
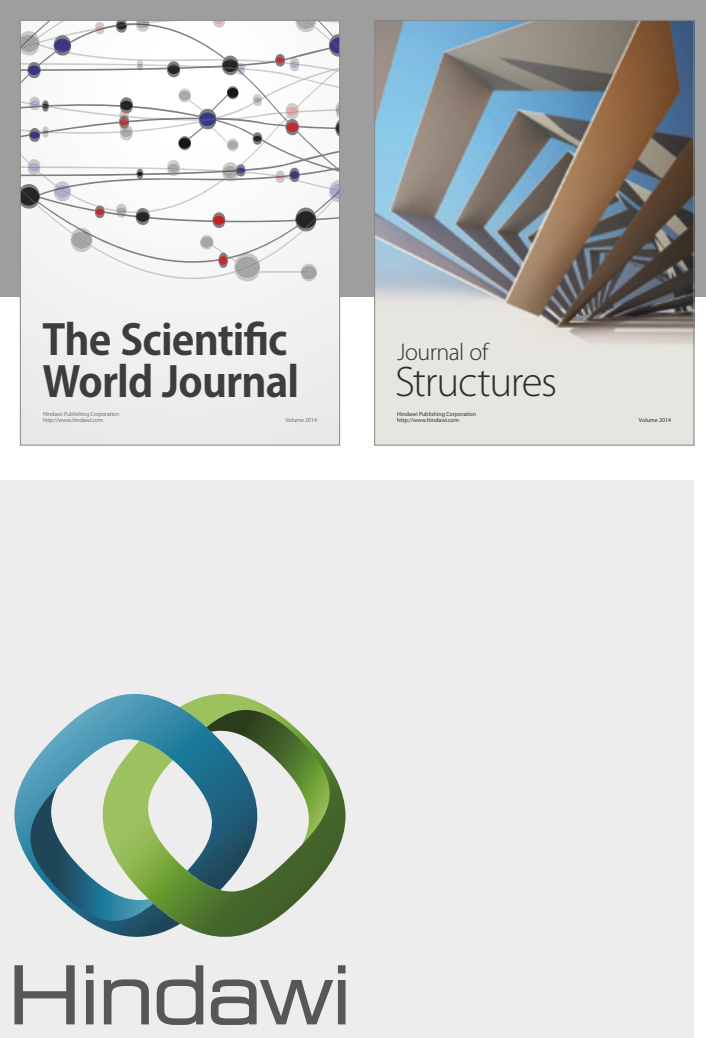

Submit your manuscripts at

https://www.hindawi.com
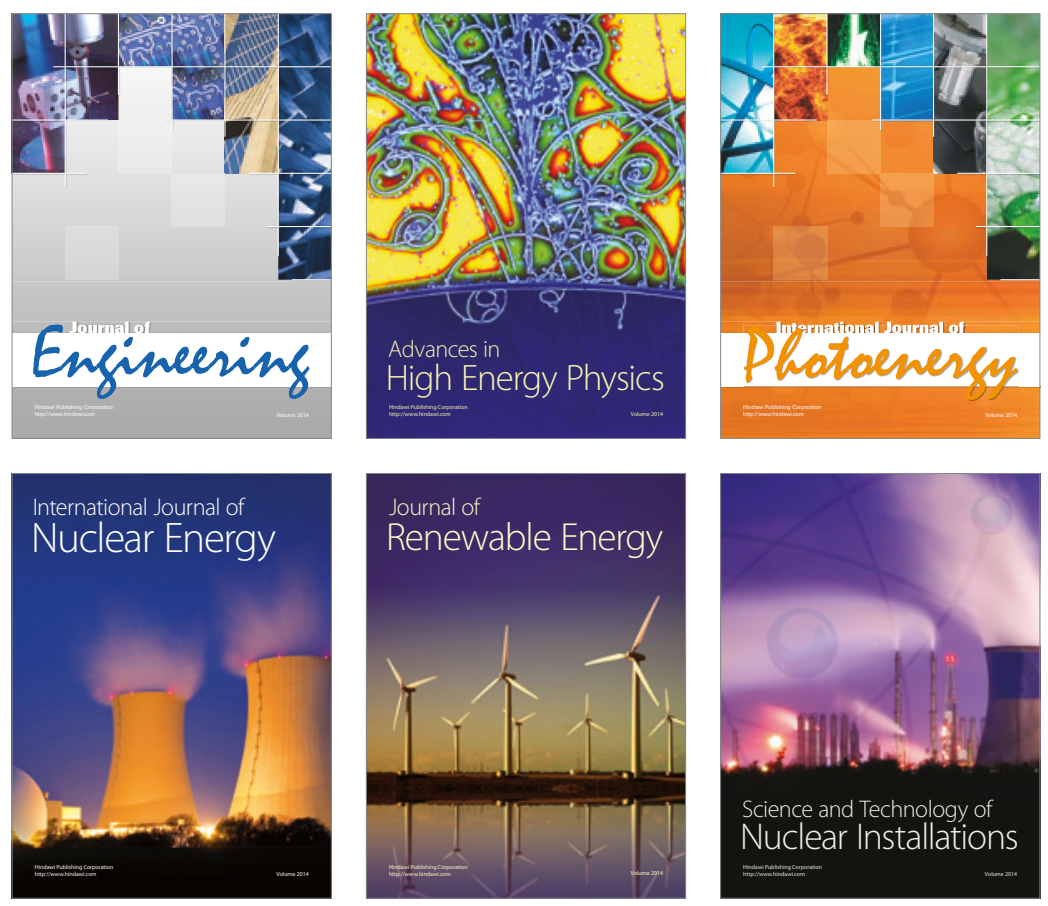

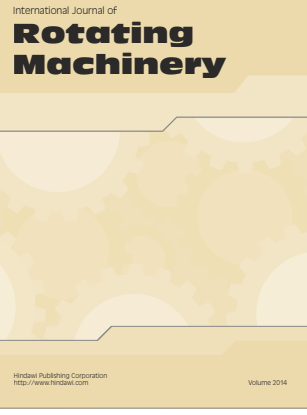

Journal of

Petroleum Engineering

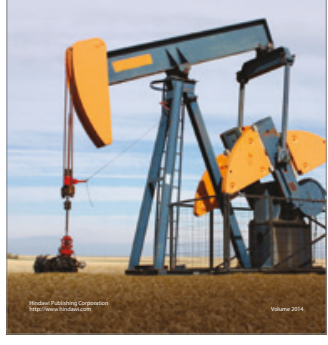

Journal of
Solar Energy
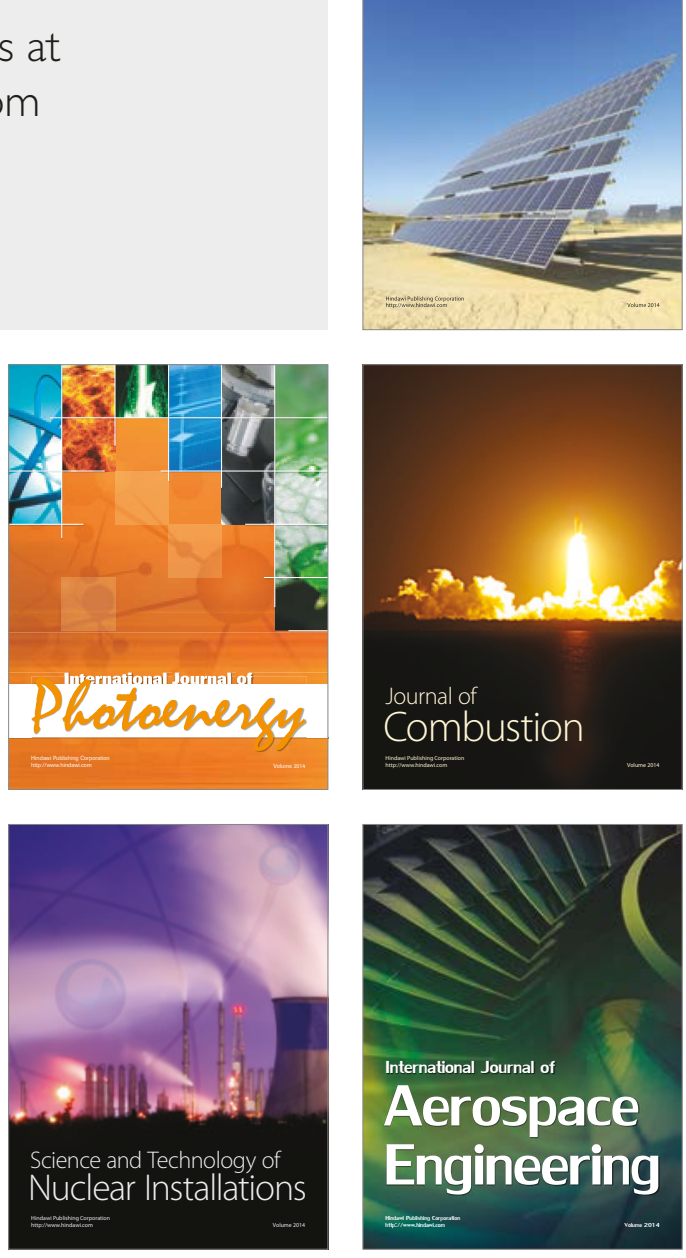